\title{
Assessment of Traffic Congestion by Traffic Flow Analysis in Pabna Town
}

\author{
Md. Tufajjal Hossain*, Md. Kamrul Hasan \\ Department of Urban \& Regional Planning, Pabna University of Science and Technology, Pabna, Bangladesh \\ Email address: \\ tufajja191@gmail.com (Md. T. Hossain), kanak.planner@gmail.com (Md. K. Hasan) \\ ${ }^{*}$ Corresponding author
}

\section{To cite this article:}

Md. Tufajjal Hossain, Md. Kamrul Hasan. Assessment of Traffic Congestion by Traffic Flow Analysis in Pabna Town. American Journal of Traffic and Transportation Engineering. Vol. 4, No. 3, 2019, pp. 75-81. doi: 10.11648/j.ajtte.20190403.11

Received: March 26, 2019; Accepted: April 29, 2019; Published: June 13, 2019

\begin{abstract}
In recent time, traffic congestion problem has become one of the most costly, both monetary and environmentally, problems in many cities all over the world. It also causes valuable time loss of citizens. Many experts suggested that the foremost step to mitigate the congestion problem is to identify traffic congestion characteristics. This study has been conducted to measure the intensity of traffic congestion of Pabna town. Traffic volume survey and spot speed study were the main methodological approaches to conduct the study. The data collected has been analyzed through the use of different statistical computer packages. Different traffic flow theories and models have also been used to calculate traffic flow parameters that expose traffic characteristics. The study has explored that auto-rickshaw, cycle rickshaw, bicycle, and motorcycle are the popular traffic mode and traffic flow becomes so intensive during the morning, noon and evening hours. It has also revealed that Ataikula road is the most congestion-prone route than A.H road and the level of services of all intersections is $\mathrm{F}$ except traffic morr which provided a comparatively better level of services to the travelers of the town. The study has also identified the major problems associated with different road sections having poor level of services.
\end{abstract}

Keywords: Traffic Congestion, Traffic Flow Analysis, Traffic Volume Survey, Pabna Town

\section{Introduction}

Climate change, natural calamities, and urban trends accelerate urban migration which is in long run responsible for the creation of serious urban traffic congestion. In developing countries, urban migration is increasing so rapidly which creates pressure on traffic flow resulting in traffic congestion. According to Gwillian (2011), per year about 3 to 5 percent population growth has occurred over the past decade in African cities due to urban migration. [1-2] This is huge for exceeding road network capacity.

Traffic congestion is defined as a situation when vehicles are slowed down below reasonable speed as the number of vehicles on a road exceeds the capacity of the road network. [3] In recent time, traffic congestion problem has become one of the most costly problems in many cities all over the world [4] It severely threatens the economy as well as the environment. [5-7] In 1997 traffic congestion produced an annual \$75 million worth Economic Wastage in Bangladesh.
[8-9]

Previous research suggested that increased level of traffic congestions helps to improve road safety which creates an ongoing debate among transport planners and safety policymakers. [10] But a recent study has revealed that road safety is not affected by the level of traffic congestions. [11]

Traffic congestion is the result of the gap between transportation demand and supply. [12] Urban inhabitants spend most of their time to roam between workplace and home. [13] The invention of motorized vehicles made their roaming easy but on contrary, it also creates trouble as concerned authority failed to cope peace with the excessive demand of infrastructure for different motorized vehicles for extra population, triggered by urban migration. [14]

As a result, traffic congestion has become a common scenario in almost every city in the world. That's why traffic congestion is worldwide recognized as a big pain of city life. [15] However, the foremost step to mitigate this problem is to identify traffic congestion characteristics. [5]

Traffic congestion is a common problem in every city of 
Bangladesh along with major metropolitan cities like Dhaka, Chittagong, Khulna and Rajshahi. [14-16] Thus, this study has been conducted to measure the intensity of traffic congestion within Pabna town by using traffic flow analysis with density and capacity calculation.

\section{Materials and Methods}

Research on short-term traffic conditions prediction has been largely concerned with parameters such as flow, occupancy, and speed, ignoring at the same time predictions during congestion, a period when predictions are needed the most. Stemming from the practical need to predict traffic parameters during congested periods, it is proposed an approach for estimating the duration of congestion on a given road section and the probability that, given its onset, congestion will end during the following time period. The Loglogistic functional form best describes congestion duration, and that the probability of congestion ending within a specified time period is likely if it has lasted up to approximately $12 \mathrm{~min}$ (with a peak at $6 \mathrm{~min}$ ). Further, if congestion lasted over $21 \mathrm{~min}$ it was probably caused by something external to the traffic system events. [15]

In order to assess the traffic congestion, traffic flow has been analyzed by measuring traffic flow variation, traffic composition, average hourly traffic, density and capacity calculation of selected roads.

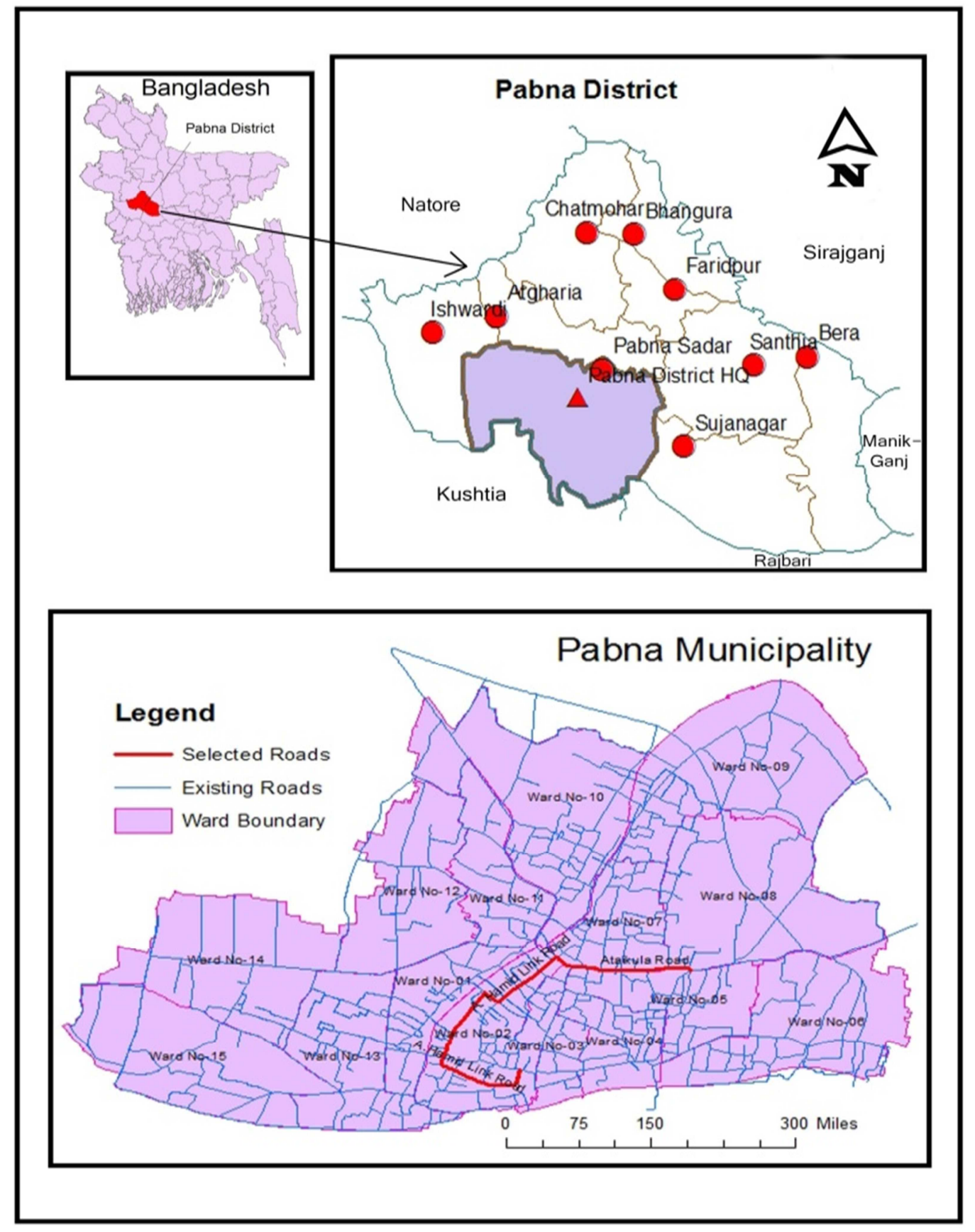

Figure 1. Study Area Location. 
Selection of the Study Area

Pabna is a secondary town in Bangladesh. It is situated at the northwestern part in Bangladesh. It is a town of Pabna district under Rajshahi division, one of eight divisions of Bangladesh. The town is the administrative capital of Pabna district.

Pabna municipality has an area of about 27 square kilometers and a population of 133403. [17] It has a road network of $187.50 \mathrm{~km}$, among $75 \%$ has bitumen surface, in the jurisdiction of different agencies like Pabna Municipality, Roads and Highway Department (RHD) and Local Government Engineering Department (LGED). [18]

Both motorized and non-motorized vehicles are observed in the town. Recently invented Auto rickshaw (also known as Borak) driven through charger battery dominants in the traffic scene of the town. Besides cycle rickshaw driven through both manually and charger battery, motorcycle, $\mathrm{CNG}$, bicycle, bus, minibus, microbus, truck are also observed on the municipality roads.

Major roads of Pabna Municipality are - Abdul Hamid Road, Ataikula Road, Thana Road/Hospital Road, College
Road, Gashpara Road, By Pass Road, Pabna-Nagarbari Road, Police Line Road, D.C. Road, and Stadium Road. Among these Abdul Hamid Road and Ataikula Road are the busiest roads in the town. Traffic congestion on these two roads has become a common daily scenario. These because five major intersections of Pabna town are located within the two roads which are - Chapa-Bibi Masjid Morr (CMM) intersection, Pachmatha Morr (PMM) intersection, Kheyaghat Morr (KGM) intersection, Traffic Morr (TM) intersection, and Indira Morr (IM) intersection. This study has been conducted to analyze traffic congestion on these five intersections.

\section{Results and Discussion}

\subsection{Existing Traffic Flow Condition of the Town}

Every road of Pabna town circulates two-way traffic. There is no regulation to control flow direction even at the intersections. Right diverging and cross movement of traffic create conflict to opposite traffic and starts woeful congestion [Figure 2].

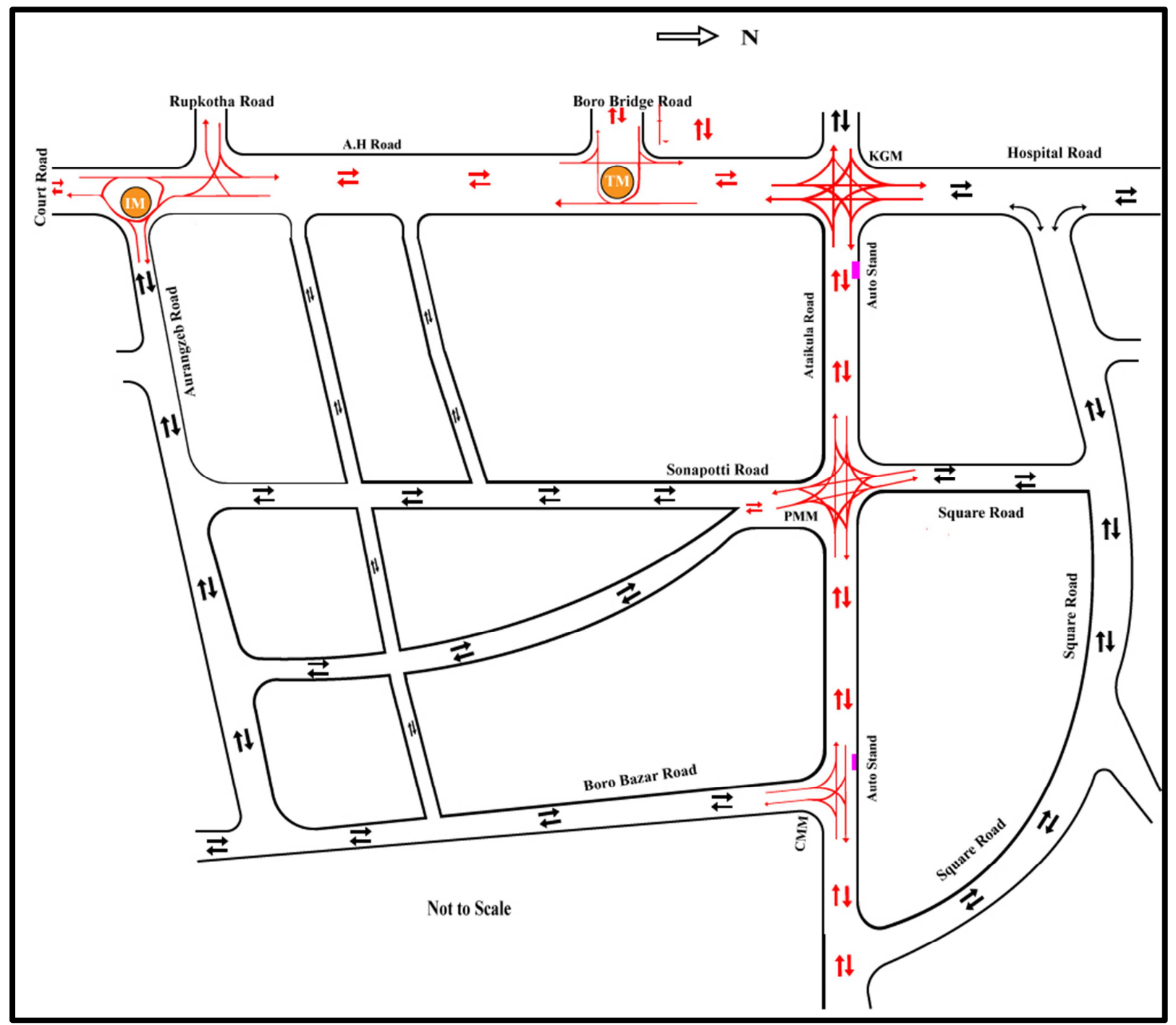

Figure 2. Direction of traffic flow of Pabna town. 
In Figure 2 the colored direction represents the studied roads. The figure shows that right diverging at CMM intersection and both right diverging and cross movement of traffic at PMM intersection creates conflict resulting in congestion on the road. Right diverging traffic at KGM intersection also creates conflict at the intersection. The figure also shows that the right diverging and cross traffic from and to Rupkotha road is responsible for creating congestion on A.H road.

\subsection{Traffic Flow Characteristics}

Traffic flow characteristics such as hourly variation of traffic flow, average hourly traffic (AHT) and traffic composition help to understand the traffic behavior of a city. It also helps to determine the peak hour in which the number of vehicles on road reaches its peak point and travel demand gets maximized. For understanding traffic flow characteristics of Pabna town traffic volume survey has executed separately for the selected roads e.g. Ataikula road and A.Hamid road. Traffic flow characteristics are discussed below.

\subsubsection{For Ataikula Road}

Traffic Flow Variation and Peak Hour Determination

To get the traffic variation scenario on Ataikula road number of vehicles passed through CMM to KGM section in every hour has converted in PCU values and it has plotted against the number of hours in a day [Figure 3]. The number of vehicles passing through the section in between $12.00 \mathrm{am}$ and 6.00 am has assumed to be negotiable.

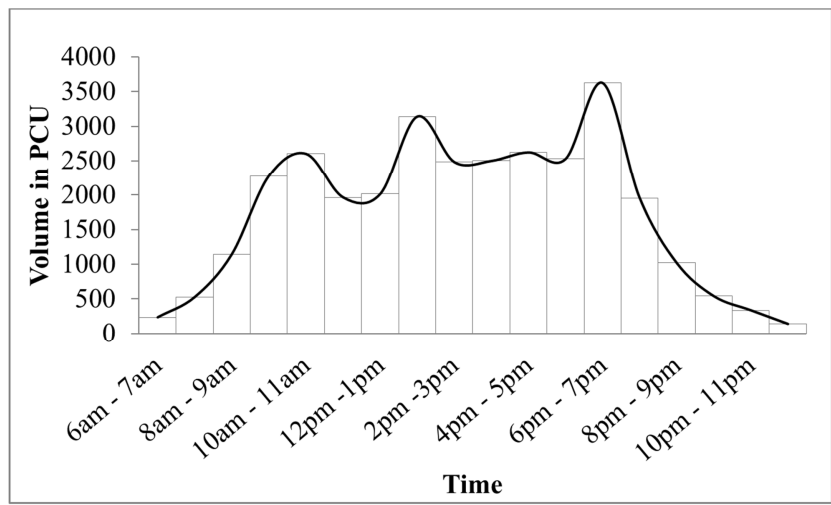

Figure 3. Traffic flow variation over a day for CMM-KGM section of Ataikula road.

Figure 3 shows that massive traffic flows in between $6 \mathrm{pm}$ and $7 \mathrm{pm}$. The PCU values get its highest point during this hour (e.g. 3624.5 PCUs) and hence this hour is determined as peak hour for Ataikula road. Shopping aspirants, employees, officials, day labors and other travelers generate mass trips for which the travel demand goes higher in the peak hour. However, students, employees, officials, and other travelers also generate notable trips between 10 am and 11 am in the morning. Again, a significant volume of traffic has observed from 1 am to $2 \mathrm{am}$. On the other hand, moderate traffic flow occurs in between $11 \mathrm{am}$ and $1 \mathrm{pm}$ and in between $2 \mathrm{pm}$ and
$6 \mathrm{pm}$.

It has been found that intensive traffic congestion occurs during these hours. Traffic congestion becomes more acute due to the lack of regulations, insufficient parking space and footpath, pick and drop off travelers here and there by auto rickshaws. Right diverging and merging and cross movement of both cycle rickshaws and auto rickshaws at CMM and PMM intersections is also responsible for creating long queuing of vehicles from Bulbul College to PMM intersection.

Average Hourly Traffic (AHT)

For CMM to KGM section of Ataikula road, the total traffic has found 31667 PCUs for a day. So, AHT is calculated 1319 PCUs for the section. It means that on average volume of 1319 PCUs of traffic pass through the road section in each hour of a day.

Traffic Composition

Traffic composition analysis gives an idea about the percentage of different types of vehicles existing in the roadstream. It helps to identify the dominant and preferable traffic mode on the road. Traffic composition for Ataikula road has analyzed from traffic volume survey and shown as a pie chart in Figure 4.

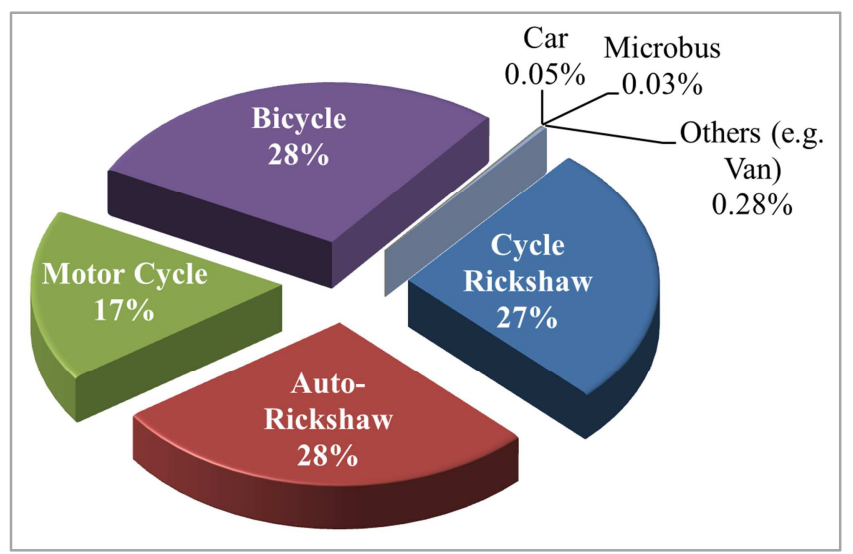

Figure 4. Field-observed traffic composition on CMM-KGM section of Ataikula road.

Figure 4 shows that auto-rickshaw, bicycle, cycle rickshaw, and motorcycle account for the major percentage as a means of traffic mode for Ataikula road. There is autorickshaw-stand nearer to the KGM intersection and Ataikula road goes towards Pabna central bus terminal from the downtown. Therefore, maximum travelers prefer autorickshaw or cycle rickshaw as public traffic mode. On the other hand, car, microbus, van etc. hold very few portions of traffic composition on Ataikula road.

\subsubsection{For A.H Road}

Traffic flow variation and peak hour determination

To get the traffic variation scenario on Ataikula road number of vehicles passed through TM to IM section in every hour has converted in PCU values and it has plotted against the number of hours in a day [Figure 4]. The number of vehicles passing through the section in between $12.00 \mathrm{am}$ and 6.00 am has assumed to be negotiable. 


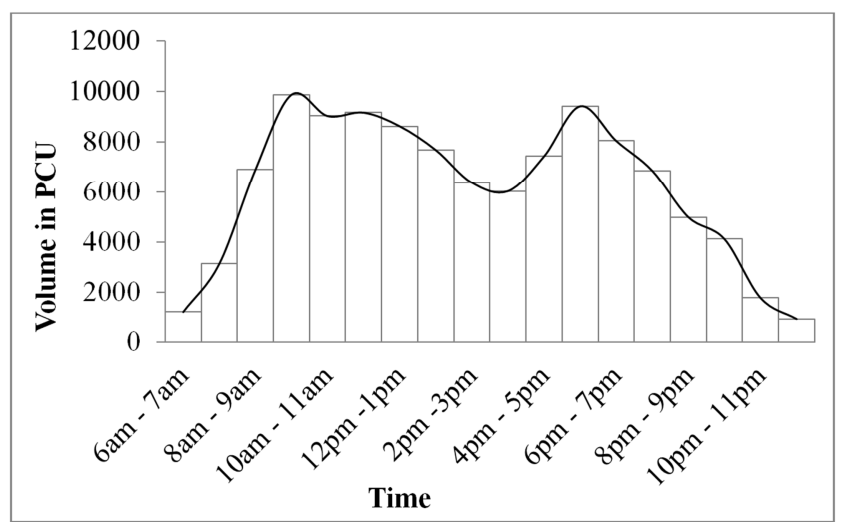

Figure 5. Traffic flow variation over a day for KGM-IM section of A.H road.

Figure 5 exposes that traffic volume becomes high in between 9 am to 10 am in the morning and $5 \mathrm{pm}$ to $6 \mathrm{pm}$ in the afternoon. The volume of traffic in peak hour is almost 9864.25 PCUs. Intensive traffic flow occurs in between 9 am to 10 am because of starting time of offices, schools, and colleges. On the other hand, the flow becomes high in the afternoon due to the ending of offices, schools and colleges and the trips that have been generated for shopping. There several commercial buildings and shopping centers alongside the A.H road. Therefore, numerous trips are attracted and hence TM-IM section of the road is made the busiest road in Pabna town. Intensive traffic congestion occurs during peak hours especially from $5 \mathrm{pm}$ to $6 \mathrm{pm}$ in the evening. Traffic congestion becomes more acute due to the lack of regulations, insufficient parking space and footpath and illegally occupied hawkers. Cross traffic from Rupkotha road, right diverging and merging traffic at IM intersection and waving traffic at TM intersection make traffic congestion more acute on A.H road.

Average Hourly Traffic (AHT)

For TM to the IM section of A.H road, the total traffic has found 111435 PCUs for a day. So, AHT is calculated 4643 PCUs for the section. It means that on average volume of 4643 PCUs of traffic pass through the road section in each hour of a day.

Figure 6 reveals that cycle rickshaw is the most dominant mode of traffic (45\%) in the TM-IM section of A.H road. The following modes are respectively motorcycle $(23 \%)$, bicycle $(11 \%)$, auto-rickshaw $(4 \%)$, and car $(1 \%)$. Very few portions of traffic composition on A.H road is claimed by bus, truck, and van.

Traffic Composition
Traffic composition for Ataikula road has evaluated from traffic volume survey and shown as a pie chart in Figure 6.

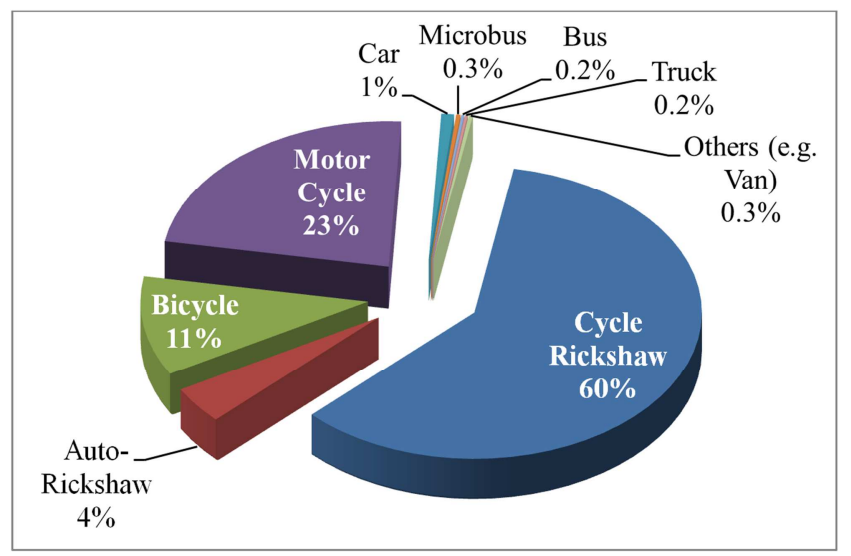

Figure 6. Field-observed traffic composition on TM-IM section of A.H road.

\subsection{Density and Capacity Calculation}

Density calculated for each section of Ataikula road and A.H road is given in the Table 1 .

Table 1 shows that the highest density occurs at CMM intersection. The $2^{\text {nd }}$ highest concentration of traffic has found at $\mathrm{KGM}$ intersection. It means that the number of vehicles presents per unit length of this intersection is so high. On the other hand, the lowest traffic concentration has found at PMMKGM section of Ataikula road indicating that less number of vehicles present per unit length of this section.

From Greenshields model [19] it has proven that there is a linear relationship between speed and density. It means that space headway between vehicles increases with the increase in speed. So, if density would zero, speeds would maximum which is known as the mean free speed and it is two times of mean speed. Again, if the speed of vehicles would zero, the density would maximum which is known as jamming density and it is two times of density at mean speed. Now, the capacity of a road section can be calculated from the mean free speed and the jammed density using the relationship -

$$
\begin{gathered}
\text { Density }=\frac{\text { Flow }}{\text { Mean Speed }} \\
\text { Capacity }=\frac{\text { mean free speed } \times \text { jamming density }}{4}
\end{gathered}
$$

\begin{tabular}{|c|c|c|c|c|c|c|}
\hline Sections & Flow (PCUs/hr) & $\begin{array}{l}\text { *Mean Speed } \\
\text { (K.P.H) }\end{array}$ & $\begin{array}{l}\text { Density } \\
\text { (PCUs/km) }\end{array}$ & $\begin{array}{l}\text { Mean free speed } \\
\text { (K.P.H) }\end{array}$ & $\begin{array}{l}\text { Jamming density } \\
\text { (PCUs/km) }\end{array}$ & $\begin{array}{l}\text { Capacity } \\
\text { (PCUs/hr) }\end{array}$ \\
\hline CMM & 1893 & 3.81 & 497 & 7.62 & 994 & 1894 \\
\hline CMM-PMM & 990 & 5.83 & 170 & 11.66 & 340 & 991 \\
\hline PMM & 2558 & 7.48 & 342 & 14.96 & 684 & 2558 \\
\hline PMM-KGM & 338 & 3.33 & 102 & 6.66 & 204 & 340 \\
\hline KGM & 1765 & 3.59 & 492 & 7.18 & 984 & 1766 \\
\hline KGM-TM & 2054 & 8.36 & 246 & 16.72 & 492 & 2057 \\
\hline TM & 6596 & 33.65 & 196 & 67.3 & 392 & 6595 \\
\hline TM-IM & 6905 & 19.11 & 361 & 38.22 & 722 & 6899 \\
\hline IM & 8315 & 18.07 & 460 & 36.14 & 920 & 8312 \\
\hline
\end{tabular}

Table 1. Calculation of density and capacity for different sections.

(*Source: Field Survey, 2018). 
In Table 1 the calculated capacity for different sections is given. Table 1 shows that IM intersection has the maximum capacity meaning the maximum number of traffic can pass through the intersection among all sections during peak hour. Due to having rotary and traffic controlled by traffic police maximum capacity has found at this intersection. On the other hand, the minimum capacity has found at PMM to KGM section where the comparatively lowest traffic can pass during peak hour.

Using Table-1 average time headway and average space headway can also be calculated [Table-2]. Table-2 shows that space headway and time head are comparatively large for PMM-KGM section meaning both space and time interval between successive vehicles passing this section from head to head are so high. As auto-rickshaw is the dominant mode of traffic in this section and there is an auto-rickshaw stand at the end of this section it requires more space for loading and unloading passengers and more time to covers spacing distance of successive vehicles. Due to the loading and unloading of passengers on street auto-rickshaw creates bottleneck condition in this section.

$$
\begin{gathered}
\text { Space headway }=\frac{1000 \times \text { Mean Speed }}{\text { Capacity }} \\
\text { Time headway }=\frac{3600}{\text { Capacity }}
\end{gathered}
$$

Table 2. Average space headway and average time headway for all sections.

\begin{tabular}{lll}
\hline Sections & Average space headway $(\mathbf{m})$ & Average time headway (sec) \\
\hline CMM & 2.01 & 1.9 \\
CMM-PMM & 5.88 & 3.63 \\
PMM & 2.92 & 1.41 \\
PMM-KGM & 9.79 & 10.59 \\
KGM & 2.03 & 2.04 \\
KGM-TM & 4.06 & 1.75 \\
TM & 5.1 & 0.55 \\
TM-IM & 2.77 & 0.52 \\
IM & 2.17 & 0.43 \\
\hline
\end{tabular}

Table-2 also shows that IM intersection has the least average time headway indicating faster movement of vehicles to cover the spacing distance. Moreover, least average headway has found at CMM intersection which indicates the high concentration and stops and goes movement of vehicles.

\subsection{Level of Service (LOS) Determination}

Level of service is the qualitative measure of operational conditions within a traffic stream. Speed drops down and the delay and frequency of stops increase when a road carries traffic equal to its capacity. Level of service in this study is determined based on the journey speed or overall travel speed for both directions for the sections [Table 3].

Table-3 shows that level of services for all sections from $\mathrm{CMM}$ to $\mathrm{KGM}$ route and the section of KGM to TM are $\mathrm{F}$ indicating jammed conditions, stop and go movement and forced flow. Diverging and cross movement of traffic at intersections, lack of footpath, illegal parking, illegal occupied hawkers alongside the road etc. cause the low speed in the sections. The conditions result in queues of vehicles.

Table 3. Level of services based on journey speed for both directions.

\begin{tabular}{llll}
\hline Sections & Overall travel speed & Level of Services [20] & Remarks \\
\hline CMM & 3.81 & F & Right diverging traffic from Boro-Bazar, auto-rickshaw parking, no traffic control \\
CMM-PMM & 5.83 & F & Auto-rickshaw parking, no footpath for pedestrians, no traffic control \\
PMM & 7.48 & F & Cross traffic from Sonapotti and Square road, illegal parking, no traffic control \\
PMM-KGM & 3.33 & F & Auto-rickshaw parking, no footpath for pedestrians, no traffic control \\
KGM & 3.59 & F & Auto-rickshaw parking, right diverging traffic from traffic Morr, have traffic control \\
KGM-TM & 8.36 & F & B \\
TM & 33.65 & D & Unauthorized hawkers alongside the road, irregular traffic control \\
TM-IM & 19.11 & D & Have rotary and traffic control \\
IM & 18.07 & & Havegal parking on streets, unauthorized hawkers on the footpath, no traffic control \\
& & traffic from Aurangzeb road toward traffic morr and from town hall to Aurangzeb road \\
\hline
\end{tabular}

Table 3 also reveals that travel speed at TM intersection is high resulting comparatively better level of service as there is a rotary at the intersection. Traffic police also inspect the movement of traffic in this intersection. It results in stable flow with delays but not unreasonable at TM intersection. On the other hand, TM to IM and IM sections have a level of services D indicating unstable flow with tolerable delays. It also indicates that there are possibilities of dropping down the level of service to $\mathrm{F}$ during peak hours.

\section{Conclusion}

Pabna is one of the ancient towns in Bangladesh. Therefore, lots of service facilities have been concentrated in the town such as university, medical college, medical hospitals, business activities etc. As a result, population of the town is increasing day by day. This increased population generates numerous trips in the town road. But transport facilities have not been developed in comparison 
with the increased population. As a result, traffic congestion has become a common scenario in the town. Citizens have to face woeful traffic jam everyday while travelling through the downtown roads of the town. On the other hand, traffic police, the one and only traffic controlling means of the town, fails to control traffic effectively, especially during peak hours, due to their human restrictions.

On top of that, traffic congestion analysis of the town has exposed that auto-rickshaw, cycle rickshaw, bicycle and motor cycle are the popular traffic mode and traffic flow becomes so intensive during morning, noon and evening. Starting and ending of office time for employment and working time for different professionals, schooling time, shopping hours, festivals and seasonal variation etc. have influence on traffic flow of the town. It has also been found that Ataikula road is the most congestion-prone route than A.H road and the level of services of all intersections is F except TM intersection. There is a rotary at TM intersection which provides a comparatively better level of services to the travelers of the town.

One-way traffic flow may be a possible solution of congestion for the town. Moreover, it has been observed that most of the commercial activities of the town take place within a very narrow space comparing to its total area. Therefore, growth centers should be developed at different important locations of the town to reduce trip generation towards the downtown of the town.

\section{References}

[1] Gwilliam, K. M. (2011): "Urban Transport: Struggling with Growth" Africa's Transport Infrastructure, World Bank, Washington, D. C

[2] Ogunleye, S. S. (2015). Trend in the Pattern of Vehicular Traffic Flow in Ado-Ekiti, South-West Nigeria. Donnish Journal of Geography and Regional Planning. Vol 1 (2). pp. 006-010.

[3] Weisbrod, G., Vary, D., \& Treyz, G. (2003). Measuring economic costs of urban traffic congestion to business. Transportation Research Record: Journal of the Transportation Research Board, (1839), 98-106.

[4] Long, J., Gao, Z., Ren, H., \& Lian, A. (2008). Urban traffic congestion propagation and bottleneck identification. Science in China Series F: Information Sciences, 51 (7), 948-964.

[5] Rao, A. M., \& Rao, K. R. (2012). Measuring Urban Traffic Congestion-A Review. International Journal for Traffic \& Transport Engineering, 2 (4).
[6] Sorensen, P., Wachs, M., Min, E. Y., Kofner, A., \& Ecola, L. (2008). Moving Los Angeles: Short-term policy options for improving transportation. Rand Corporation.

[7] Wang, G., Gao, Z., Xu, M., \& Sun, H. (2014). Joint link-based credit charging and road capacity improvement in continuous network design problem. Transportation Research Part A: Policy and Practice, 67, 1-14.

[8] Meenar, R. M. M. (2000). Traffic Congestion in Dhaka City: where is the solution? Term paper for the Coarse PD 592: Infrastructure and Transport Planning, Department of planning, Sunny buffalo, May 10, 2000.

[9] Khuda F., M., A., S., (2010). The Intensity of Traffic Congestion: A Case Study on Mirpur Road (Unpublished Bachelor's Thesis). Jahangirnagar University.

[10] Shefer, D., and Rietveld, P. (1997). "Congestion and safety on highways: Towards an analytical model." Urban Stud., 344, 679-692.

[11] Quddus, M. A., Wang, C., \& Ison, S. G. (2009). Road traffic congestion and crash severity: econometric analysis using ordered response models. Journal of Transportation Engineering, 136 (5), 424-435.

[12] Habib, K. M. N. (2002). Evaluation of planning options to alleviate traffic congestion and resulting air pollution in Dhaka City. Department of Civil Engineering, Bangladesh University of Engineering and Technology, Dhaka, 1-157.

[13] Catanese, A. J. (Ed.). (1972). New perspectives in urban transportation research. Lexington Books.

[14] Chowdhury, T. U., Raihan, S. M., Fahim, A., \& Bhuiyan, M. A. (2016). A Case Study on Reduction of Traffic Congestion of Dhaka City: Banani Intersection. In International Conference on Agriculutural, Civil and Environmental Engineering (ACEE-16).

[15] Stathopoulos, A., \& Karlaftis, M. G. (2002). Modeling duration of urban traffic congestion. Journal of Transportation Engineering, 128 (6), 587-590.

[16] Gilbert, R., \& Perl, A. (2013). Transport revolutions: moving people and freight without oil. New Society Publishers.

[17] BBS (2005): Statistical Year Book of Bangladesh, Bangladesh Bureau of Statistics (www.bbs.gov.bd), Government of Bangladesh

[18] MIDP (2008). Municipal Infrastructure Development Plan for Pabna Paurashava, Pabna

[19] Greenshields, B. D., Channing, W., \& Miller, H. (1935). A study of traffic capacity. In Highway research board proceedings (Vol. 1935). National Research Council (USA), Highway Research Board.

[20] Kadyali, D. L. (1987). Traffic engineering and transportation planning. 